\title{
A MOBILIDADE URBANA SOLIDÁRIA NO ESTATUTO DA CIDADE E SUA CONCRETIZAÇÃO PELA VIA DA ECONOMIA COLABORATIVA
}

\section{THE SOLIDARY URBAN MOBILITY IN THE STATUTE OF CITY AND ITS REALIZATION THROUGH THE COLLABORATIVE ECONOMY}

\author{
Mariana Ribeiro Santiago ${ }^{1}$ \\ Leonardo de Carvalho Peixoto ${ }^{2}$
}

\section{RESUMO}

O presente estudo, valendo-se do método dialético e procedimentos histórico, comparativo, empírico e funcionalista, baseados em pesquisa bibliográfica e com referencial teórico na solidariedade, procurou demonstrar que o capitalismo atual desprovido de solidariedade e em desacordo com a sustentabilidade necessita de uma reflexão, em especial quanto ao tema mobilidade urbana, que gera diversas discussões. A mobilidade urbana solidária, com base na economia colaborativa, pode ser uma alternativa para a consecução da sustentabilidade e pode colaborar para minimizar os problemas de mobilidade encontrados em diversas partes do Brasil e do mundo. Para que a solidariedade na mobilidade gere reflexos na sociedade deve-se averiguar a sua compatibilização com os instrumentos legais existentes, portanto, procurou-se investigar se o Estatuto da Cidade seria compatível com a mobilidade urbana solidária para que fosse confirmada sua viabilidade no contexto da legislação pertinente. Assim, conclui-se que uma mobilidade urbana solidária é parte de uma mobilidade urbana sustentável, onde todos os envolvidos, particulares, Estado, empresas e organizações não governamentais são os responsáveis para a sustentabilidade no campo da mobilidade urbana com base na solidariedade.

\footnotetext{
${ }^{1}$ Pós-Doutora em Direito Civil, pela Justus-Liebig-Universität Giessen (Alemanha). Doutora em Direito Civil Comparado, pela Pontifícia Universidade Católica de São Paulo - PUCSP. Professora do Programa de Mestrado e Doutorado em Direito da Universidade de Marília - UNIMAR. Editora-Chefe da Revista Argumentum. Membro do Projeto Harmony with Nature, das Nações Unidas. E-mail: mari.santiago@terra.com.br

${ }^{2}$ Mestrando em Direito da Universidade Marília - UNIMAR, Especialista pela Universidade de Uberaba UNIUBE, Professor do curso de Direito da UNIC-Rondonópolis-MT e da UNIASSELVI-Rondonópolis-MT, Advogado, Analista de Meio Ambiente - perfil Advogado da Secretaria de Meio Ambiente do Estado de Mato Grosso-SEMA/MT. E-mail: mariana@nbsadvogados.com.br
} 
Palavras-chave: Mobilidade urbana. Solidariedade. Sustentabilidade. Estatuto da Cidade. Consumo colaborativo.

\section{ABSTRACT:}

The present study using the dialectical method and historical, comparative, empirical and functionalist procedures, based on bibliographical research and with theoretical reference in solidarity, sought to demonstrate that current capitalism devoid of solidarity and in disagreement with sustainability needs a reflection, especially on the subject of urban mobility that generates diverse discussions. Solidarity-based urban mobility, based on collaborative economics, can be an alternative to achieving sustainability and can collaborate to minimize the mobility problems found in various parts of Brazil and the world. In order for solidarity in mobility to generate reflexes in society, its compatibility with existing legal instruments must be investigated. Therefore, an attempt was made to investigate whether the Statute of City would be compatible with solidarity urban mobility so that its viability could be confirmed in the context of legislation relevant. Thus, it is concluded that solidarity urban mobility is part of a sustainable urban mobility, where all stakeholders, individuals, the State, companies and non-governmental organizations are responsible for sustainability in the field of urban mobility based on solidarity .

Keywords: Urban mobility. Solidarity. Sustainability. Statute of the City. Collaborative consumption.

\section{INTRODUÇÃO}

Os estudos sobre mobilidade urbana com base na solidariedade apresentam pouca investigação, em especial quando envolvem a economia colaborativa, pois a discussão sobre economia colaborativa acaba destacando-se sobre os seus efeitos na mobilidade urbana, sendo deixada a escanteio das discussões.

Por isso procurou-se inverter essa situação determinando as condições sociais que propiciassem o ressalto do tema mobilidade urbana solidária, com o uso da econômica colaborativa, na atual sociedade e sua compatibilidade com o instrumento mais importante da legislação brasileira sobre cidades, ou seja, o Estatuto da Cidade (Lei n.10.257/2001).

Importante esta análise tendo em vista o crescimento do problema da mobilidade urbana no Brasil e em todo mundo; dessa forma procura-se demonstrar que o envolvimento de particulares, Estado, empresas e organização governamentais (stakeholders) são o caminho para a 
sustentabilidade e que esse caminho obrigatoriamente passa por uma sociedade solidária, inclusive demonstrando iniciativas de mobilidade urbana solidária, com base na economia colaborativa, como fundamento para essa possibilidade de uma mobilidade urbana sustentável.

A presente pesquisa foi realizada utilizando o método de abordagem dialético, porque penetra o mundo dos fenômenos por meio de sua ação recíproca, da contradição inerente ao fenômeno e da mudança dialética que ocorre na natureza e na sociedade que serão aplicadas ao tema para se chegar à conclusão, e métodos de procedimentos empírico, histórico, comparativo e funcionalista; empregando a técnica da documentação indireta, visto que a pesquisa foi bibliográfica.

Parte-se de um referencial teórico baseado na solidariedade social, com vistas a preservação da presente e futuras gerações, amplamente defendida por Edgar Morin (2015), para defender a figura da mobilidade urbana solidária e sua compatibilidade com o Estatuto da Cidade.

Assim o trabalho inicia-se contrapondo as figuras da solidariedade e do capitalismo, buscando evidenciar o modo de vida capitalista individualista/consumista e os desafios para a passagem para um modo de vida coletivista/solidário com base num capitalismo sustentável, fundado no equilíbrio entre economia, meio ambiente e justiça social.

Após isso, é apresentado o Estatuto da Cidade e a Política Nacional de Mobilidade Urbana com seus objetivos e instrumentos, verificando se eles são compatíveis com a mobilidade urbana solidária, baseada na economia colaborativa, e se apresentam no seus contextos a sustentabilidade e a solidariedade.

A partir deste entendimento de como a sociedade está e para onde ela deve caminhar, passou-se a definir a mobilidade urbana solidária, com base na economia colaborativa, esclarecendo o que vem a ser a mobilidade urbana sustentável e a economia colaborativa e como esses dois instrumentos são promotores da denominada mobilidade urbana solidária.

\section{SOLIDARIEDADE E CAPITALISMO: UMA INTERFACE POSSÍVEL}

O Século XX foi marcado pela expansão do capitalismo no mundo, em especial com a queda do muro de Berlim e o fim da União Soviética. Países que continuam com o status de socialistas, como a China, renderam-se à abertura de mercado. Esta tendência se intensifica no Século XXI, gerando cada vez mais dúvidas sobre o futuro da humanidade, dado o crescimento populacional, a finitude dos recursos naturais e a exacerbada degradação do ambiente natural, artificial e do trabalho. 
A globalização calcada na expansão capitalista e no ideal de desenvolvimento fundado exclusivamente na economia, ao propiciar privatização dos serviços públicos e empresas de Estado, substituição das atividades públicas por atuações privadas, primazia dos investimentos especulativos internacionais, desregulamentações etc., tem gerado várias crises socioambientais, ampliando todos os aspectos negativos do desenvolvimento. (MORIN, 2015, p. 29)

O movimento desenvolvimentista capitalista tem como principal característica a economia de mercado. Suas referências são o consumo e o crédito, que movimentam a economia e movem os mercados sempre na direção de oferecer à sociedade a ideia de que precisa-se possuir bens de consumo para se obter inclusão social.

Esse referencial capitalista consumista impõe às pessoas a ideia de que cada um deve possuir bens para alcançar a felicidade, estimulando o desejo de aquisição de novos produtos, mais modernos e atraentes, porém supérfluos. Como consequências, pode-se elencar o aumento do desperdício e exclusão social. (SIRVINSKAS, 2017, p. 93)

Se é verdade que a produção e o consumo proporcionam maior arrecadação de tributos e aumento do emprego, não se pode olvidar que maior consumo significa também maior pressão sobre os recursos naturais e, consequentemente, degradação ambiental e diminuição da qualidade de vida. Consumir sem se preocupar com o futuro pode incentivar, ainda, a competição, exacerbar o materialismo, a ganância, o egoísmo e, essencialmente, a falta de ética. (SIRVINSKAS, 2017, p. 93)

Tal fenômeno individualiza as pessoas, desestimula a cooperação, a divisão e o reaproveitamento, convencionando o desejo individualista capitalista desenvolvimentista econômico, que compartimentaliza os indivíduos uns em relação aos outros, conferindo-lhes apenas parte limitada das responsabilidades. Perde-se de vista, assim, o conjunto, o global, a solidariedade. (MORIN, 2015, p. 30)

O estimulo desenvolvimentista econômico atinge as atividades cooperativas, solidárias e de reaproveitamento, faz com que as degradações sociais e ambientais sejam intensificadas, pois apenas a manutenção da ordem econômica é valorizada pelo modo de vida capitalista, moldador de pessoas individualistas, numa "metástase do ego". (MORIN, 2015, pp. 69-70)

O egocentrismo exacerbado gera ignorância e irresponsabilidade em relação aos acontecimentos socioambientais, aumentando os riscos nesta seara, especialmente os voltados a qualidade de vida. Como exemplos, pode-se citar o aumento da poluição do solo, do ar e da água, áreas de urbanização precária, o lixo, o trânsito, as doenças, a miséria, a escassez dos recursos naturais, entre outros. 
O atual contexto social, econômico e ambiental parece não ter solução, no entanto, medidas simples podem colaborar para a diminuição da degradação e o aumento das potencialidades dos produtos e seu reaproveitamento. Nesse sentido, ensina SIRVINSKAS (2017, p. 93):

É preciso incentivar as práticas ecologicamente corretas no nosso dia a dia, buscando um novo estilo de vida, calcado na ética e no humanismo em resgatar e criar novos valores e repensar nossos hábitos de consumo. Criar, enfim, uma sociedade sustentável tendo com base a educação ambiental.

Modificações no pensamento capitalista podem colaborar para a reorganização das sociedades com vistas ao presente e futuro das relações sócio-econômico-ambientais, melhorando a qualidade de vida, envolvendo a sociedade, o Estado, as empresas e outras organizações, como as ONG (Organizações não governamentais).

ELKINGTON (2012, pp. 33-135) acredita no denominado capitalismo de stakeholders, ou seja, um capitalismo que se preocupa com todos os envolvidos nas relações econômicas, sociais e ambientais como uma alternativa. O referido autor prega a sustentabilidade fundada na linha dos três pilares - triple bottom line - onde para se ter sustentabilidade todos os envolvidos devem basear suas decisões nos pilares econômico, social e ambiental.

A sustentabilidade dos três pilares se baseia em comportamentos solidários que propiciem uma mudança de pensamento e atitude de todos os envolvidos, a nortear e garantir o futuro da humanidade. Sustentabilidade e solidariedade são, dessa forma, conceitos intimamente ligados.

De acordo com MORIN (2005, p. 36) , acerca do tema da solidariedade:

Em nosso mundo de homens, no qual as forças de separação, recolhimento, ruptura, deslocamento, ódio, são cada vez mais poderosas, mais do que sonhar com a harmonia geral ou com o paraíso, devemos reconhecer a necessidade vital, social e ética de amizade, de afeição e de amor pelos seres humanos, os quais, sem isso, viveriam de hostilidade e de agressividade, tornando-se amargos ou perecendo.

HABERMAS (2000, pp. 75-76) defende que justiça e solidariedade são temas indissociáveis, no sentido de que:

A justiça concebida deontologicamente exige, como sua outra face, a solidariedade. Não se trata, neste caso, de dois momentos que se complementam, mas de aspectos da mesma coisa. Toda moral autônoma tem que resolver, ao mesmo tempo, duas tarefas: ao reivindicar trato igual, e com ele um respeito equivalente pela dignidade de cada um, faz valer a inviolabilidade dos indivíduos na sociedade; e ao mesmo tempo em que exige 
a solidariedade por parte dos indivíduos, como membros de uma comunidade na qual são socializados, protege as relações intersubjetivas de reconhecimento recíproco. A justiça refere-se à igualdade da liberdade dos indivíduos que se determinam a si mesmos e que são insubstituíveis, enquanto a solidariedade refere-se ao bem, ou à felicidade dos companheiros irmanados em uma forma de vida intersubjetivamente compartilhada, e deste modo também à preservação da integridade dessa forma de vida. As normas não podem proteger um sem o outro, isto é, não podem proteger a igualdade de direitos e as liberdades dos indivíduos sem o bem do próximo e da comunidade a que eles pertencem.

A Constituição Brasileira de 1988, a par da legitimação do sistema capitalista, traz expressa, no inciso I, de seu artigo 3으, a determinação de que constitui objetivo fundamental da República Federativa do Brasil "construir uma sociedade livre, justa e solidária", dentre outros. Para SIRVINSKAS (2017, p. 165),

A Constituição Federal quer proteger o meio ambiente para as presente e futuras gerações como princípio da ética e da solidariedade entre elas. A continuidade da vida depende da solidariedade da presente geração no que diz com o destino das futuras gerações, criando-se o princípio da responsabilidade ambiental entre gerações.

A solidariedade, enquanto sentimento a impor a cada pessoa deveres de cooperação, assistência e amparo em relação às outras, surge, assim, como categoria ética e moral recepcionada pelo mundo jurídico, galgando grande importância por permitir a conscientização acerca da interdependência social. (LÔBO, 2009, p. 81)

Não se deve confundir, contudo, solidariedade e caridade. Esta, fora de dúvida, marca a superioridade moral duma sociedade, mas basta sancioná-la, de acordo com a linguagem do direito, para que se torne um dever de justiça, confundindo-se os campos de atuação de cada uma. (RIPERT, 2002, p. 268)

A solidariedade ingressa no sistema jurídico como uma forma de atribuir significado ao próximo, despertando no indivíduo o reconhecimento da existência do outro, porque estimula em cada um a consciência perceptiva do ambiente social. Torna-se, assim, um novo paradigma para o direito, que, visando melhorar o Estado, a sociedade e a qualidade de vida dos cidadãos, implica um sistema jurídico que valoriza a dignidade plena do ser humano e a responsabilidade social de todos, no qual não se encaixam a indiferença social e o egoísmo individual exacerbado. (CARDOSO, 2010, pp. 109, 116 e 122) 
Por outra perspectiva, a solidariedade, ao buscar a igualdade entre os indivíduos como fim, pressupõe situações de desigualdade, pois age exatamente no espaço da diferença entre os mesmos. Esta desigualdade é o objeto da solidariedade. (DI LORENZO, 2010, p. 132)

A partir da ideia de solidariedade, pode-se imaginar uma economia onde há uma preocupação com a qualidade de vida de todos e não só com o indivíduo. Isso não significa falta de desenvolvimento ou crescimento. Pelo contrário, mostra-se necessário desenvolver produtos e serviços que minimizem os problemas socioambientais ocasionados pela busca incessante do crescimento econômico.

As atividades econômicas solidárias são uma alternativa na linha do desenvolvimento sustentável. Por outro lado, numa perspectiva de complexidade, outras atividades devem decrescer para que o objetivo da sustentabilidade seja alcançado. Dentro dessa perspectiva, MORIN (2015, pp. 43-44) ensina que:

A orientação crescimento/decrescimento significa que é preciso fazer crescerem os serviços, as energias verdes, os transportes públicos, a economia plural, da qual a economia social e solidária, a organização de instalações visando a humanização das megalópoles, as agriculturas e criações de gado rurais e biológicas, mas decrescerem as intoxicações consumistas, a comida industrializada, a produção de objetos descartáveis e não recicláveis, a dominação dos intermediários (principalmente os grandes hipermercados) sobre a produção e consumo, o tráfego de automóveis particulares, o transporte rodoviário de mercadorias (em prol do ferroviário).

A tarefa de desprendimento do individualismo capitalista atual para um coletivismo solidário de um capitalismo sustentável é árdua, mas não impossível, pela via da economia solidária, em suas diversas vertentes. O presente estudo visa tratar especificamente da solidariedade aplicada à mobilidade urbana, ligada às alternativas para a deficiência do transporte público no Brasil, em combate aos efeitos colaterais da produção, comercialização e uso exacerbados de veículos.

\section{MOBILIDADE URBANA SOLIDÁRIA NO ESTATUTO DA CIDADE}

Em especial em relação ao automóvel, cuja utilização massificada tem atuado como um complicador nas questões do urbanismo moderno, que privilegia preceitos de sustentabilidade e 
solidariedade social, a mobilidade urbana é um tema constantemente tratado do ponto de vista privado.

Os problemas de mobilidade urbana estão ligados, entre outros fatores, ao fato das cidades terem crescido desordenadamente, sem planejamento de infraestrutura, desde transporte público até o tráfego, e sem um estudo de crescimento sustentável, ao que se soma o fenômeno da multiplicação de áreas de urbanização precária e as longas distâncias a serem percorridas para se ter acesso ao trabalho, lazer, comércio, serviços públicos, dentre outros. Deste modo, necessário se faz pensar as cidades. (MORIN, 2015, p.248)

Um grande passo para se pensar as cidades foi a promulgação da Lei n.10.257/2001, denominada de Estatuto da Cidade. Por consequência deste instrumento normativo, em 2003 foi criado o Ministério das Cidades, e, em 2012, foi criada Lei n.12.587/2012 que trata da Política Nacional de Mobilidade Urbana.

Todos estes instrumentos alçaram a mobilidade urbana como um problema de Estado, a quem compete fazer com que a legislação seja efetiva, sendo assim corresponsável com o particular por sua aplicação. Tal mudança de paradigma, ligada à solidariedade social, está bem descrita na obra de MAGAGNIN (2008, p. 11), para quem

Com a criação da Secretaria Nacional de Transporte e da Mobilidade Urbana - cuja sigla é SeMob (Ministério das Cidades), toda a política referente as questões de transporte, agora denominada política de Mobilidade Urbana Sustentável, está sob sua guarda e responsabilidade. Esta mudança de nomenclatura (denominação) vem ampliar o antigo conceito de Planejamento de Transportes, incorporando as questões de sustentabilidade e da participação popular, além das questões tradicionais de transporte e circulação.

A legislação é um grande passo para consecução da mobilidade urbana solidária. O Estado deve acompanhar e regularizar as atividades privadas, minimizando o risco da desordem, que não é o intuito do Estatuto da Cidade e nem da Política Nacional de Mobilidade Urbana, pelo contrário eles visam compatibilizar o uso do solo urbano de modo racional, gerando o mínimo de impacto econômico, social e ambiental.

O objetivo da política de Mobilidade Urbana Sustentável é proporcionar o desenvolvimento dos princípios da Mobilidade Urbana Sustentável através de três eixos principais: i) Desenvolvimento urbano; ii) Sustentabilidade ambiental e iii) Inclusão social. (MAGAGNIN, 2008, p.11). 
Veja que a mobilidade urbana sustentável desenvolve-se na linha dos três pilares apresentada por ELKIGNTON, portanto, todos os envolvidos são detentores do direito e do dever de fomentar a mobilidade urbana sustentável, inclusive com o apoio aos sistemas de economia colaborativa para mobilidade solidária indicadas no capítulo anterior.

Dois instrumentos previstos no Estatuto da Cidade podem ser ressaltados na questão da mobilidade urbana, estes são o plano diretor e o zoneamento urbano (parcelamento do solo), além deles a utilização o Estudo de Impacto de Vizinhança, também, é bastante útil para preservação da mobilidade urbana sustentável.

O plano diretor está previsto nos artigos 39 à 42 da Lei n.10.257/2001 (Estatuto da Cidade), servindo para planejamento das cidades e é obrigatório para as cidades com mais de vinte mil habitantes; para as cidades com mais de quinhentos mil habitantes o plano diretor deve trazer um plano de transporte urbano integrado ( $\$ 2^{\circ}$ do artigo 41 ).

A Secretaria Nacional de Transporte e da Mobilidade Urbana recomenda que os planos diretores tragam quatro itens principais sobre mobilidade urbana: Hierarquização viária (diferenciação de circulação entre transporte público, veículos particulares, pedestres e cicloviários), Zoneamento da mobilidade (delimitação das áreas de circulação de todas as espécies viárias), Sistema de monitoramento da mobilidade (indicadores sobre mobilidade) e Base de dados para o planejamento continuado (elaboração de mapas, tabelas e outros instrumentos para o processo de gestão). (MAGAGNIN, 2015, pp.15-16).

O parcelamento do solo, com a inclusão, no plano diretor, dos objetivos expressos nas alíneas do inciso IV, do artigo 2º, da Lei n.10.257/2001 (Estatuto da Cidade), sinaliza na direção do urbanismo, pois se analisa o potencial da área para acesso a todos os serviços com intuito de alcançar a qualidade de vida. A alínea " $d$ " traz especificamente "a instalação de empreendimentos ou atividades que possam funcionar como pólos geradores de tráfego, sem a previsão da infra-estrutura correspondente", visa direcionar as atividades para que não se concentrem gerando congestionamentos ou falta de acesso.

Por último a utilização do Estudo de Impacto de Vizinhança (EIV), previsto no inciso VI, do artigo 4o e artigos 36 à 38 todos da Lei n.10.257/2001 (Estatuto da Cidade), é um instrumento que traz à tona, para as questões urbanas e de mobilidade, a sustentabilidade nas bases da linha dos três pilares defendida por ELKINGTON; isto porque o artigo 37 diz que devem ser analisados no estudo sete pontos: adensamento populacional; equipamentos urbanos e comunitários; uso e ocupação do solo; valorização imobiliária; geração de tráfego e demanda por transporte público; ventilação e iluminação; e paisagem urbana e patrimônio natural e cultural. 
Evidente que a geração de tráfego e demanda por transporte público é especifica da mobilidade urbana, no entanto os demais pontos congregam as cidades sustentáveis e, por conseguinte, a mobilidade urbana sustentável, uma vez que agrega diversos pontos da economia, meio ambiente e os interesses sociais.

Outras questões podem ser regulamentadas para compatibilizar a mobilidade urbana à solidariedade, através da tributação, pedágios urbanos, proibição de circulação, rodízios de veículos, transportes públicos eficientes e mais baratos etc., como entende MORIN (2015, pp.260-261)

Os transportes públicos e privados deveriam ser não poluentes (automóveis elétricos ou híbridos). Pedágios urbanos poderiam ser instituídos, como aconteceu em Londres, o que reduziu consideravelmente o tráfego vindo de fora da cidade. Bicicletas e automóveis de aluguel estariam a disposição de todos. Para os transportes fora das zonas de pedestres, a conscientização cidadã estimularia o uso de caronas, de táxis coletivos e de triciclos elétrico para o transporte de mercadorias. Os ônibus a gasolina seriam substituídos pelos metrôs e trens, que poderiam servir amplamente os espaços urbanos e periféricos.[...].

As iniciativas sugeridas por MORIN dependem de todos os envolvidos, regulamentação do Estado, participação comunitária, envolvimento de empresas e de organizações não governamentais. O Estatuto da Cidade é o precursor legislativo da gestão compartilhada das cidades, prevista nos artigos 43 à 45 da Lei n.10.257/2001, denominada Gestão Democrática das Cidades.

Uma associação entre esses diversos atores [stakeholders] precisa ser consolidada ou existir a fim de criar uma força comum capaz de agir no âmbito de uma gestão combinada. Essa capitalização de todas as experiências exitosas em matéria de gestão urbana compartilhada, a fim de perenizá-las e transformá-las em ensinamentos aplicáveis em outras partes, evidentemente, adaptando-se às particularidades e especificações de cada caso. (MORIN, 2015, p.257).

A gestão das cidades para uma mobilidade urbana sustentável e solidária, através da utilização dos instrumentos previstos no Estatuto da Cidade, do envolvimento dos particulares, a regulamentação e estímulos públicos e privados para as atividades de economia colaborativas de mobilidade e a conscientização de que o ambiente urbano depende das atitudes voltadas ao alcance de um capitalismo sustentável são o caminho para a consecução da sustentabilidade e promoção da solidariedade para a presente e futuras gerações.

O inciso I, do artigo 2o da Lei 10.257/2001 (Estatuto da Cidade) traz expressa a solidariedade ao dispor da seguinte forma: "garantia do direito a cidades sustentáveis, entendido como o direito à 
terra urbana, à moradia, ao saneamento ambiental, à infra-estrutura urbana, ao transporte e aos serviços públicos, ao trabalho e ao lazer, para as presentes e futuras gerações."

Logo, o Estatuto da Cidade e a Política Nacional de Mobilidade Urbana são leis que se compatibilizam com a mobilidade urbana solidária, pois ambos estão voltados a sustentabilidade e a participação de todos os envolvidos na mudança de pensamento e comportamento exigidos para a preservação da humanidade.

\section{ECONOMIA COLABORATIVA COMO ALTERNATIVA DE MOBILIDADE URBANA SOLIDÁRIA}

O excesso de automóveis em circulação tem gerado diversos problemas de mobilidade urbana, em especial, nas grandes cidades, além de provocar poluição, congestionamentos, estresse, dentre outros males. Os custos financeiros de se adquirir um automóvel também devem entrar nesta alta conta econômica, social e ambiental, pois incluem aquisição, manutenção, combustível, seguro, impostos, pedágios e local para guardá-lo.

[...] o automóvel concentra em si todas as virtudes e todos os vícios. Máquina utilitária e máquina de diversão, pequena casa sobre rodas - para os homens, animal doméstico fiel, esposa amante de forma arredondadas e de interiores macios; para mulheres macho de aço superpoderoso dominado e subjugado, que infantiliza o adulto e adultifica o adolescente, que barbariza o civilizado e civiliza o bárbaro, estabelecendo a soberania do Eu enquanto insere e sua concha como um escargô, libertadora e alienante, símbolo e instrumento de uma independência que subjuga, alternativamente individualista, familiar, amorosa, ninho de voluptuosidade para os amantes e pomo de discórdia entre casais, de velocidade embriagadora e de lentidão apaziguadora, concha protetora e tanque de assalto, que desencadeia a vontade de poder na divina aceleração e na curva divertida, que estimula estratégias hábeis na selva urbana, mas que é impotente nos engarrafamentos, transformando o cidadão pacífico em monstro feroz, que favorece individualismo humano e, ao mesmo tempo, a animalidade sanguinária, que exalta a vida, mas no risco de morte, por ser rápido, confortável e pessoal, o automóvel é o mais racional dos modos de transporte para a cidade, para o campo, para o trabalho, para o lazer, e, simultaneamente, o mais irracional de todos, porque provoca engarrafamentos, atrasos, estresse, nervosismos, os quais o rádio e a música anestesiam um pouco, e produz enormes poluições e gastos de energia, $\mathrm{O}$ automóvel nos dá a liberdade na escravidão, nos dá mobilidade para melhor nos imobilizar nos engarrafamentos. (MORIN, 2015, p.307-308). 
Como expresso no capítulo anterior a sociedade pós-moderna é individualista/consumista e pouco coletivista/solidária. Uma metáfora muito interessante sobre essa sociedade consumista é a que diz que a sociedade está correndo num deserto e sobre uma fina camada de gelo congelada de um lago, ou seja, não se sabe para onde ir e se parar irá rachar a camada de gelo e afundar. (BAUMAN, 2001, pp.07-267).

A sociedade encontra-se banhada pelo "ter" sem saber o porquê "ter", esquece-se da função de ter algum bem pelo status de ter o bem, o veículo é reflexo dessa sociedade sem rumo que nem sabe o porquê adquiriu algum produto e ignora os malefícios que ele pode causar ao todo (coletivo social). Muitas pessoas têm automóveis pelo simples fato de ter, mesmo que não o aproveite ou o aproveite mal.

Além do mais, as campanhas publicitárias mercantilistas das empresas fabricantes de automóveis aliadas à sociedade consumista, criam esta sociedade onde o "ter" é mais valorosos que o "ser" e as pessoas compram esta ideia de que "ter" um automóvel the garante felicidade e liberdade.

Na verdade esta expressão de liberdade plena da sociedade pós-moderna não é verdadeira, uma vez que, infelizmente, a sociedade pós-moderna adota uma única lei que a rege, a Lei de Mercado. (BAUMAN, 2001, pp.07-267).

A observância ao tripé da sustentabilidade no contexto da pós-modernidade inclui a análise de meios alternativos para a compatibilização ou harmonização do consumo e da preservação do desenvolvimento social e econômico, sem olvidar da preocupação com a preservação dos recursos naturais e da exploração indispensável à existência humana, onde se faz necessária a exposição acerca da experiência do consumo colaborativo. (SANTIAGO; BEZERRO, 2017, p.474).

Percebe-se, portanto, que esse estudo não visa a discussão da mobilidade urbana através do transporte público, que deve sempre ser o principal investimento em mobilidade e que está a cargo, em regra do Estado; o que se pretende é demonstrar que existem alternativas fundadas em modelos solidários com base na disseminação da economia colaborativa para melhoria da mobilidade urbana através dos meios privados de deslocamento, em especial o automóvel, tendo por finalidade demonstrar sua compatibilização com o Estatuto da Cidade.

Primeiramente tem-se que entender o que é mobilidade urbana, o inciso II, do artigo 4음 Lei n.12.587/2012 (Lei da Política Nacional de Mobilidade Urbana) informa que mobilidade urbana é a "condição em que se realizam os deslocamentos de pessoas e cargas no espaço urbano." 
Porém, o conceito legal é ao mesmo tempo amplo e restrito, pois parece atender objetivamente o que é mobilidade urbana, mas não traz consigo a ideia de sustentabilidade, deste modo, melhor definição deve envolver a chamada mobilidade urbana sustentável.

[...] Assim, a mobilidade urbana sustentável pode ser definida como o resultado de um conjunto de políticas de transporte e circulação que visam proporcionar o acesso amplo e democrático ao espaço urbano, através da priorização dos modos não motorizados e coletivos de transportes, de forma efetiva, socialmente inclusiva e ecologicamente sustentável, baseado nas pessoas e não nos veículos. (BOARETO, 2003, p.49).

Nesse sentido o que interessa é a otimização do uso ou a não utilização do automóvel como uma alternativa para melhorar a mobilidade urbana, ou seja, a circulação no espaço urbano com menor impacto possível.

Outra conceituação necessária para o entendimento deste capítulo é o de economia colaborativa ou economia compartilhada que "é constituída por práticas comerciais que possibilitam o acesso a bens e serviços, sem que haja, necessariamente, a aquisição de um produto ou troca monetária" (SILVEIRA et.al., 2016, p.300).

Em outras palavras seria o reaproveitamento e a otimização do ócio gerado pela aquisição de produtos e serviços, otimizando sua utilização e minimizando os impactos negativos do consumo baseado somente no "ter", já que diversas vezes não é necessário adquirir novos produtos.

Nesse contexto, é legitimo pensar se a economia, no seu sentido amplo, como o conjunto das atividades que contribuem para a produção e a distribuição de riquezas, pode resumir-se ao circuito clássico da circulação de riquezas constituído pelas esferas do Estado e do mercado nas sociedades contemporâneas. Não seria possível uma forma alternativa de economia? (FRANÇA FILHO; LAVILLE, 2004. p. 15)

Já é realidade, em diferentes partes do mundo, uma outra espécie de economia, gestada a partir de iniciativas, sobretudo de natureza cooperativista e associativista, oriundas da sociedade civil e dos meios populares. Mostra-se sob diferentes configurações: criação coletiva do próprio circuito de produção e consumo, alimentando cadeias socioprodutivas autônomas e, em alguns casos, não-monetarizadas, ou diferentes tipos de parcerias com os poderes públicos. É o que se chama de economia colaborativa-solidária. Como exemplos, projetam-se os bancos populares, clubes de trocas e as cooperativas sociais. (FRANÇA FILHO; LAVILLE, 2004. p. 15)

De fato, mostra-se necessária uma mudança na mentalidade sobre o uso de produtos e já se difundem mundialmente sistemas lastreados na ideia de que se pode obter benefícios dos bens sem possuí-los definitivamente, o que repercute no modelo de propriedade privada individual. O que se 
percebe é que, se um produto de uma empresa é compartilhado entre pares, isso maximiza a sua utilidade, sem que os usuários devam arcar com o ônus da propriedade, como pagar completamente pelo valor do produto, manutenção ou seguro. (BOTSMAN; ROGERS, 2011, p. 61)

As motivações daqueles que participam desse tipo de economia são diversas. Alguns, mais altruístas, na defesa do "consumo verde", mostram-se preocupados com as gerações futuras, os aspectos sociais ou simplesmente buscam um relacionamento mais estreitos com pessoas e não marcas. Outros estão focados numa urgência prática de economizar dinheiro ou tempo, ou seja, mantendo a crença no interesse próprio. (BOTSMAN; ROGERS, 2011, p. 60)

As iniciativas de economia solidária e consumo colaborativo em diferentes partes do mundo, em verdade, apresentam semelhanças com algumas tendências históricas e culturais de organização de grupos sociais do passado, que ressurgem ou se revigoram na modernidade, combinando a dimensão comunitária tradicional e a moderna dimensão pública na sua ação. (FRANÇA FILHO; LAVILLE, 2004. pp. 17-18)

O estudo de diversos exemplos do consumo colaborativo demonstra que, na essência, eles devem compartilhar quatro orientações fundamentais: (1) a influência da massa crítica, (2) o aproveitamento da capacidade ociosa de coisas e habilidades, (3) a crença no bem comum e (4) a confiança entre desconhecidos, sendo que nenhum destes pontos é considerado mais importante do que o outro, embora, em alguns casos, um deles possa ser mais desenvolvido, fundamentando o funcionamento do sistema, do que outros. (BOTSMAN; ROGERS, 2011, p. 64)

A massa crítica popular descreve a existência de um impulso suficiente em um sistema para fazê-lo funcionar de forma autossustentável, desde reações de consumo nucleares em cadeia à adoção em larga escala de novas tecnologias. Ela é vital para o consumo colaborativo por dois motivos: a satisfação nas escolhas e a "prova social". (BOTSMAN; ROGERS, 2011, p. 64)

Embora não exista uma fórmula universal a determinar o ponto certo da massa crítica, tendo em vista que isso é variável em razão do contexto de cada negócio, das necessidades em jogo e das expectativas dos usuários, o princípio é o mesmo: cada sistema específico de consumo colaborativo será bem-sucedido e se firmará no mercado se os usuários estiverem satisfeitos com as opções de escolha e com a conveniência à sua disposição. (BOTSMAN; ROGERS, 2011, pp.66-68)

A segunda razão da importância vital da massa crítica para o consumo colaborativo é que um grupo central de primeiros usuários, fiéis e frequentes, uma vez atraído, proporciona uma "prova social" de que estas formas de negócio são algo que os outros deveriam experimentar, influenciando as pessoas em geral a cruzarem a barreira psicológica que muitas vezes existe em torno de novos 
comportamentos, que fogem a um modelo tradicional de consumo. (BOTSMAN; ROGERS, 2011, pp. 68-69)

De acordo com Rachel Botsman e Roo Rogers (2011, p. 70),

a prova social é fundamental para o consumo colaborativo porque a maioria das formas geralmente exige que as pessoas façam alguma coisa um pouco diferente e que elas mudem velhos hábitos. Para que elas se convençam a fazer a mudança, a maioria das pessoas precisa ver ou experimentar uma massa crítica de consumidores que também fazem a troca. Muitas vezes decidiremos o que fazer ou o que não fazer de acordo com o que as pessoas à nossa volta estão fazendo.

Outro ponto a se considerar é o potencial ocioso de um produto quando ele não está sendo usado, chamado de capacidade ociosa. O desperdício não está ligado apenas ao lixo, mas à quantidade de coisas que possuímos e não utilizamos. Por exemplo: o carro fica ocioso em média 22 (vinte e duas) horas por dia, o quarto de hóspedes raramente é utilizado, o vestido de noite depende de uma ocasião especial para ser usado etc. O consumo colaborativo implica em calcular como podemos aproveitar esta capacidade ociosa, não apenas dos bens, mas de habilidades em geral, e redistribuí-la em outro lugar. (BOTSMAN; ROGERS, 2011, pp. 70-71, 73)

Já a crença nos bens comuns é uma reação à deturpação dos conceitos de propriedade privada e cercamentos, que se espalharam rapidamente pela Europa e pelos Estados Unidos durante os séculos XVIII e XIX, justificando-se pela lógica errônea de que os recursos, se compartilhados, estariam sujeitos ao uso excessivo e indevido pelos indivíduos, supostamente sempre influenciados de acordo com os seus interesses próprios de curto prazo. (BOTSMAN; ROGERS, 2011, pp. 74-75)

A história tem demonstrado, todavia, que tal visão limitada da propriedade privada e dos indivíduos, que faz apologia a uma tragédia inevitável, não é sempre a melhor ou a única resposta. A Internet, apenas a título exemplificativo, é o bem comum mais robusto que já existiu, e o seu espaço está cada vez mais firmado na sociedade moderna. (BOTSMAN; ROGERS, 2011, pp. 75-76)

Outro exemplo bastante salutar foi criado pelo professor de direito de Stanford, Lawrence Lessig, o qual dedicou boa parte de sua carreira a estudar, pesquisar e promover o valor de um bem comum de ideias culturais, educacionais e científicas. O referido professor, reconhecendo a necessidade de facilitar o compartilhamento, a recombinação e a reutilização de conteúdos criativos - músicas, fotos, conhecimento e filmes, lançou, em 2002, o Creative Commons, que oferece licenças gratuitas de direitos autorais para incentivar o compartilhamento de materiais e a colaboração. (BOTSMAN; ROGERS, 2011, pp. 75-76) 
Tal iniciativa, lastrada na ideia de bem comum, representa uma solução para a falha no compartilhamento, criando uma cultura significativa de socialização online que nos estimula a compartilhar, contando, atualmente, com mais de 100 (cem) milhões de licenças, emitidas em 52 (cinquenta e dois) países, e possuindo usuários ilustres, como a Casa Branca, nos Estados Unidos. (BOTSMAN; ROGERS, 2011, pp. 75-76)

Mas, para que o ciclo do consumo colaborativo seja eficiente, é preciso, ainda, que os usuários das suas redes, pessoas desconhecidas, em diferentes graus, confiem umas nas outras. É preciso que se acredite que as pessoas envolvidas são inofensivas, honestas, e que o produto apresenta mesmo as características informadas. (BOTSMAN; ROGERS, 2011, p. 77)

No mundo do hiperconsumo, intermediários, como assistentes de vendas, gerentes, corretores, negociadores, mediadores, agentes e distribuidores, acabam por preencher a lacuna de confiança entre produtores e o consumidores. Mas o consumo colaborativo elimina a necessidade destes tipos de intermediários, ou, pelo menos, redefine o seu papel, que deixa de ser o de simplesmente fiscalizar o comércio, para que passem a funcionar como curadores e embaixadores, criando plataformas que facilitem as trocas e as contribuições autogeridas. (BOTSMAN; ROGERS, 2011, p. 77)

Resgatada, na prática, a confiança, através de sistemas próprios desenvolvidos para aferição de reputação dos negociantes, a serem melhor elucidados adiante, a tendência é de que voltemos a uma época em que os erros e constrangimentos causados por um agente do sistema se tornarão, facilmente, de conhecimento de toda a comunidade. Os caronas, os vândalos e os abusadores serão facilmente eliminados, da mesma maneira que a abertura, a confiança e a reciprocidade serão estimuladas e recompensadas. (BOTSMAN; ROGERS, 2011, p. 80)

Mas como a economia colaborativa pode ser alternativa para a mobilidade urbana? $\mathrm{Na}$ verdade já existem iniciativas no Brasil e no mundo onde se pratica a mobilidade urbana solidária. Essas práticas visam minimizar os congestionamentos e diminuir os impactos relacionados a produção e uso de automóveis, melhorando a mobilidade urbana nas cidades.

Muitas vezes os automóveis são utilizados apenas por uma pessoa para seu deslocamento, contudo há ociosidade do uso do automóvel que normalmente pode levar mais quatro pessoas além do condutor, a disponibilização destes lugares no automóvel, de forma gratuita ou onerosa para outras pessoas, otimiza o uso do veículo e diminui quatro automóveis em circulação, veja, a maximização gera agilidade e minimiza os impactos gerados pelos veículos. Tem-se aí a aplicação da solidariedade gerando sustentabilidade e melhor qualidade de vida. 
No Brasil e no mundo existem diversas experiências de mobilidade urbana solidária. Empresas como Uber, Cabfy, 99POP, Televo, Willgo (FARIA, 2016) são aplicativos de transporte privado onde o usuário solicita uma corrida por preços menores que os táxis, que também são alternativas para a mobilidade. A diferença é que a ideia inicial destes aplicativos, quando do seu surgimento, era que os proprietários de veículos disponibilizassem as vagas ociosas dos automóveis e poderiam, ainda, lucrar com isto.

Na prática, o que houve foi a transformação do uso das vagas ociosas em atividade remunerada por muitas das pessoas que começaram a disponibilizar seus veículos particulares a serviço dos aplicativos de transporte privado. No entanto, esses aplicativos não deixam de ser uma alternativa de mobilidade urbana solidária, já que diversas pessoas, principalmente em grandes centros como São Paulo e Rio de Janeiro, venderam seus veículos e estão utilizando unicamente os serviços dos aplicativos, devido aos altos custos de manutenção, aquisição e uso do automóvel.

Outra iniciativa de mobilidade urbana solidária são empresas que oferecem compartilhamento de veículos como a Car2go, a maior do mundo, onde através do aplicativo o interessado verifica onde tem um veículo mais próximo disponível, entra no veículo e se desloca até outro ponto da cidade onde deixará o veículo para que outro usuário o utilize.

No Brasil, existem diversas empresas de compartilhamento de automóveis, como a Zazcar, Pegcar, Parpe, Olacarro, Mobbie, Vamo e Urbano, sendo que as três primeiras, juntas, já possuem 65 mil usuários. Essa modalidade de compartilhamento peer to peer está em expansão no Brasil. (FUSSY, 2017).

Existem, também, os aplicativos de carona como Blablacar, Bynd, Caronetas, Mobiag, Carona direta, Meleva, Zaznu, dentre outros, onde pessoas que se deslocam na mesma direção dão carona a outras revezando seus veículos ou utilizando apenas um veículo, muitos pais já fazem isso há bastante tempo quando levam seus filhos e de vizinhos ou amigos para escola, os aplicativos apenas ampliaram as possibilidades. (MIWA, 2016).

MORIN (2015, p.309) apresenta como via reformadora para o que ele denomina "desintoxicação do automóvel" a carona compartilhada, dentre outras alternativas. Além dessas alternativas motorizadas existe, ainda, a substituição do automóvel pela bicicleta ou o compartilhamento de bicicletas que podem ser utilizadas de ponto a ponto, deixando os automóveis fora de locais que não comportariam o excesso de veículos, melhorando a mobilidade nestes locais.

A economia colaborativa pode ser um interessante instrumento de mobilidade urbana baseada na solidariedade e sem a necessidade de intervenção do Estado, já que dependem da 
atitude coletiva/solidária em detrimento do individualismo/consumista, porém, o Estado deve estimular tais atividades e, também, se possível, regulamentar, para que não haja abusos.

As empresas/start ups responsáveis por todos estes aplicativos e sistemas de economia colaborativa de mobilidade urbana solidária estão no caminho da função social e solidária esperadas das empresas, especialmente quando se busca a sustentabilidade pela linha dos três pilares de ELKINGTON.

Se o Estado deve estimular e até regulamentar a mobilidade urbana solidária, o Estatuto da Cidade é importante instrumento para sua realização, e as iniciativas públicas devem caminhar em paralelo com as iniciativas privadas, para que a solidariedade seja direito e dever conforme expresso na Constituição Brasileira.

\section{CONSIDERAÇÕES FINAIS}

Os instrumentos demonstrados ao longo do estudo apresentam a dimensão da problemática da sociedade atual em relação à sustentabilidade, revelando uma sociedade individualista/consumista deterioradora do meio ambiente e da justiça social, em prol somente da economia.

A sustentabilidade não existe sem o tripé economia, ambiente e sociedade. No contexto aqui apresentado, a sustentabilidade, com base na linha os três pilares de ELKINGTON e na solidariedade defendida por MORIN, fundamenta a possibilidade de se ter uma mobilidade urbana solidária estabelecida com base na economia colaborativa.

O desmascaramento do Estado na sociedade pós-moderna, ou seja, a descoberta da ineficiência estatal na sociedade atual, não o isenta de participação como regulamentador e incentivador de ações de mobilidade urbana solidária, até porque o Estatuto da Cidade, assim como a Política Nacional de Mobilidade Urbana, expressam uma mobilidade urbana sustentável.

Todo o contexto legal não pode ser deixado de lado, pois a base solidária esta incrustada na legislação sobre mobilidade urbana. Dessa forma, a mobilidade urbana solidária com base na economia colaborativa, apesar de ser iniciativa privada, não deixa de fazer parte de um processo de gestão pública de mobilidade.

O envolvimento da sociedade, empresas, Estado e organizações não governamentais está diretamente relacionado ao sucesso da solidariedade na mobilidade urbana, sempre com a finalidade de sustentabilidade. 
O Estatuto da Cidade é a lei de política urbana brasileira, portanto, as atividades de mobilidade urbana devem estar de acordo com seus instrumentos. Como demonstrado, o Estatuto da Cidade revolucionou a política urbana e trouxe ao arcabouço legislativo fundamento para práticas de solidariedade voltada para sustentabilidade das cidades, incluídas as práticas de mobilidade urbana, evidenciadas pela elaboração de outro instrumento normativo especializado, que é a Política Nacional de Mobilidade Urbana.

A partir do Estatuto da Cidade é que os municípios puderam adotar medidas legais de controle de mobilidade urbana, como o rodízio de carros em São Paulo e outras iniciativas, como as leis regulamentadoras de aplicativos de corridas particulares, inclusive impondo a estes regras para melhor atender as políticas públicas. A sustentabilidade voltada a solidariedade compatibiliza-se com a mobilidade urbana solidária, fundada na economia colaborativa, assim como com o Estatuto da Cidade.

\section{REFERÊNCIAS}

BAUMAN, Zygmunt. Modernidade líquida. Tradução Plínio Dentzien. Rio de Janeiro: Zahar, 2001.

BOARETO, Renato. A mobilidade urbana sustentável. Revista dos Transportes Públicos, ANTP, Ano 25, 3o trimestre, 2003. pp.45-56. Disponível em http://filesserver.antp.org.br/_5dotSystem/download/dcmDocument/2013/01/10/15FBD5EB-F6F4-4D95B4C4-6AAD9C1D7881.pdf . Acesso em 02 fev 2018.

BOTSMAN, Rachel e ROGERS, Roo. O que é meu é seu: como o consumo colaborativo vai mudar o nosso mundo. Tradução Rodrigo Sardenberg. Porto Alegre: Bookman, 2011.

BRASIL. Constituição da República Federativa do Brasil de 1988. Disponível em http://www.planalto.gov.br/ccivil_03/constituicao/constituicao.htm. Acesso em 07 dez 2017.

BRASIL. Lei n.10.257 de 10 de julho de 2001 (Estatuto da Cidade). Disponível em http://www.planalto.gov.br/Ccivil_03/leis/LEIS_2001/L10257.htm. Acesso em 02 fev 2018. 
BRASIL. Lei n.12.587 de 03 de janeiro de 2012 (Política Nacional de Mobilidade Urbana). Disponível em http://www.planalto.gov.br/ccivil_03/_ato2011-2014/2012/lei/l12587.htm. Acesso em 02 fev 2018.

CARDOSO, Alenilton da Silva. Princípio da solidariedade: o paradigma ético do direito contemporâneo. São Paulo: Juarez de Oliveira, 2010.

DI LORENZO, Wambert Gomes. Teoria do Estado de solidariedade: da dignidade da pessoa humana aos seus princípios corolários. Rio de Janeiro: Elsevier, 2010.

ELKINGTON, John. Sustentabilidade, canibais com garfo e faca. São Paulo: M.Books do Brasil Editora, 2012.

FARIA, Larrissa. Testamos os novos concorrentes do Uber. Veja São Paulo - Caderno Cidades, publicado em 24 de junho de 2016. Disponível em https://vejasp.abril.com.br/cidades/concorrentesdo-uber-aplicativos-carro/. Acesso em 02 fev 2018.

FRANÇA FILHO, Genauto Carvalho de e LAVILLE, Jean-Louis. A economia solidária: uma abordagem internacional. Porto Alegre: Editora da UFRGS, 2004.

FUSSY, Peter. Compartilhamento de carros cresce e ganha mais opções no Brasil. G1, São Paulo, publicado em 07 de julho de 2017. Disponível em https://vejasp.abril.com.br/cidades/concorrentesdo-uber-aplicativos-carro/. Acesso em 02 fev 2018.

HABERMAS, Jürgen. Aclaraciones a la ética del discurso. Madrid: Trotta, 2000.

LÔBO, Paulo Luiz Netto. Direito civil: parte geral. São Paulo: Saraiva, 2009.

MAGAGNIN, Renata Cardoso. Um sistema de suporte à decisão na internet para o planejamento da Mobilidade Urbana. Tese (doutorado), Programa de pós-graduação em engenharia civil, Escola de Engenharia de São Carlos da Universidade de São Paulo, 2008. Disponível em http://www.teses.usp.br/teses/disponiveis/18/18137/tde-21052008-173849/en.php. Acesso em 02 fev 2018. 
MORIN, Edgar. A via para o futuro da humanidade. Tradução Edgard Assis Carvalho, Marisa Perassi Bosco. 2 ed. Rio de Janeiro: Bertrand Brasil, 2015.

MORIN, Edgar. O Método VI: ética. Tradução de Juremir Machado da Silva. 2 ed. Porto Alegre: Porto Alegre: Sulina, 2005.

MIWA, Jessica. Onze aplicativos de carona solidária para gastar menos (e aliviar o trânsito). Disponível em http://www.mobilize.org.br/noticias/9543/11-aplicativos-de-carona-solidaria-para-voce-gastarmenos-e-aliviar-o-transito.html. Acesso em 02 fev 2018.

RIPERT, Georges. A regra moral nas obrigações civis. Campinas: Bookseller, 2002.

SANTIAGO, Mariana Ribeiro; BEZERRO, Eduardo Buzetti Eustachio. Relações de consumo na pósmodernidade: o consumo colaborativo como instrumento de sustentabilidade. Revista de Direito da Cidade, vol.09, no2, p.463-468.

SILVEIRA, Lislene Mello da; PETRINI, Maira; SANTOS, Ana Clarrisse Matte Zanardo dos. Economia compartilhada e consumo colaborativo: o que estamos pesquisando?. REGE - Revista de Gestão, 23, 2016. pp. 298-305. Disponível em https://ac.els-cdn.com/S1809227616306063/1-s2.0S1809227616306063-main.pdf?_tid=5996a556-0854-11e8-af8f00000aab0f26\&acdnat=1517602081_2fbdbfa2d41c2efb533a449c8a3c1989. Acesso em 02 fev 2018.

SIRVINSKAS, Luis Paulo. Manual de Direito Ambiental. 15 ed. São Paulo, Saraiva, 2017.

Trabalho enviado em 27 de agosto de 2018

Aceito em 11 de janeiro de 2019 